\title{
Changing demands on Canada's forests and impacts on timber supply: An environmental perspective
}

\author{
by Paul Griss ${ }^{1}$
}

\section{An Historical Perspective on Timber Supply}

Five years ago, I gave my very first presentation on forest issues. The event was the CIF annual conference, which that year had as its theme, "perception is reality". My remarks will focus to a large extent on the perception of timber supply. As an example, let me say that my wife and I drove here to Kananaskis, and in thirty-six hours of driving there were only a few hours where trees were not the dominant feature on the landscape. It's thus hard to rationalize the concern over reductions in timber supply, although I recognize that it is a very serious problem in certain regions.

By way of introduction, let me state a few selected quotes that are pertinent to the issue.

Without immediate action to stop climate change, much of our northern forest is unlikely to survive our childrens' lifetimes.

\section{Kevin Jardine, Greenpeace, 1994}

The depletion of some of the more accessible forest resources, the rise in wood costs, and the growth of the market for wood products have increased the incentive for long range planning in forest operations.

and

More recently, shortages of low cost wood have led to technological developments that have permitted a greater proportionate use of hardwoods, and other softwoods which, in earlier days, were bypasssed.

Royal Commission on Canada's Economic Prospects, 1957

Most of the present generation of adults were brought up in the pleasant belief that the forest resources of Canada were infinite and inexhaustible; that nature had provided more than we could possibly use and asked nothing of us but to appropriate her gifts as we needed them ... It was not until well into the twentieth century that the realization began to grow, at first only among those closely in touch with the forests, that the new methods of exploitation, and rapidly expanding field of usefulness of the forest trees, involved a rate of consumption which, if maintained along with the old and wasteful methods of forestry administration and the old recklessness about accidental loss, would soon bring the accessible part of the forest near to the vanishing point.

B.K. Sandwell, 1930

We are recklessly destroying the timber of Canada, and there is scarcely the possibility of replacing it.

Sir John A. MacDonald, 1871

${ }^{1}$ Consultant in natural resources policy and management.

A paper presented at the Timber Supply in Canada Conference, Kananaskis, Alberta, 15-18 November, 1994.
As long as some people have been cutting trees, other people have felt that too much was being cut, yet logging in Canada has steadily increased. Public concern has been expressed at regular intervals throughout the history of forest exploitation in Canada, approximately every thirty years or so (perhaps as each succeeding generation looks at what it might be inheriting or passing on to its children). All of the above quotes address concerns over the loss of forests, but deal with very different things.

These expressions of concern have become more intense as the level of exploitation of the forests has increased. The root causes for the concerns are given less attention generally than the aspect of forest management that prompted the present day alarm. As a result, each wave of concern has been met by rosy assurances by the industry, which attempts to downplay public concerns, and also each wave has been met with progressively more stringent regulations and constraints on the industry designed to address the particular issue of concern to the critics.

Today, the issue that is the focal point of timber supply concerns is the environment. Environmental protection is the latest scapegoat for many of the underlying problems that have accompanied the expansion of the forest industry in Canada.

\section{Timber Supply and the Environment}

I was asked to provide an environmental perspective on timber supply, but try as I might I can't find one. There is no "environmentally correct" approach to timber supply and all sources of fibre generate environmental concerns. Industry can secure additional fibre in four general ways.

\section{(a) Expansion}

For much of the history of forest exploitation in Canada, industry found additional fibre by moving into previously untouched areas. Today, most of the forest landbase is already allocated and existing allocations are increasingly challenged by those who want to use the forest for other purposes, which usually were not considered at the time the allocations were made. The expansionist approach to timber supply results in land use conflicts relating to land claims, the establishment of parks and wilderness areas, and competition with remote tourism operators. Further expansion of the industry will be bitterly contested.

\section{(b) Efficiency}

A second source of additional fibre is through improved efficiency. Industry can get more use out of each tree either through finding productive uses for "waste" or by taking their products back for recycling. In the former case, the industry opens itself to attack for felling old-growth forests to make telephone books, or for leaving too little waste on site which may compromise regeneration efforts. Recycling also presents a range of problems relating to increased energy use, de-inking of recycled paper, and sludge disposal. It's hard to see how sending boxcars full of used newsprint from Tennessee to northem Ontario has any environmental benefit, despite the merits of recycling. 


\section{(c) Productivity}

Another source of fibre is increased productivity. The industry can grow more fibre more quickly through intensive forest management and the establishment of fast-growing plantations. This, too, has environmental consequences as it generates concerns over the level of manipulation of the forests, reductions in biodiversity, and constraints on other forest values.

\section{(d) Alternatives or New Technologies}

Finally, industry can examine alternative sources of fibre, or employ new technologies to either replace existing sources of fibre or stretch them farther. Alternatives, such as hemp or kenaf, may be substituted for certain uses in the coming years if they prove economically feasible. These alternatives may not be free from criticism as they may result in the use of marginal lands, the application of chemical fertilizers and pesticides, and other perils associated with agricultural practices.

It is clear that there is no magic wand out there that will dissipate public concerns over timber supply. The question therefore becomes how do we address public concerns and at the same time ensure a secure supply of fibre for the industry?

\section{The Search for Security}

Until very recently, the industry has had a very secure supply of timber since much of the commercially valuable and accessible forest was at its disposal. Any constraints on the landbase allocated to timber production, whether imposed for economic, social or environmental reasons, were considered a "withdrawal", implying that the best and highest use of all forests was for timber production. Given this reality, any areas that have been logged out are simply evidence that the industry has not been sustainable in that region, and are signs of bad planning or management.

In most cases, though, the challenge to timber supply results from a changing mix of demands on the forest brought about by the development of the region, which may entail economic diversification, a growing population, or increasing demand for recreational usage of the forest. There is also a growing awareness of the ecological importance of the forests among the general public. These threats to the security of timber supply are largely value-driven and timber supply becomes a matter of allocation of the forest among an increasingly fractious range of users.

This reality requires an adaptive approach from industry, which has become the quest for sustainability. Today, we are all striving to define "sustainable forest management" and how it can be achieved. Sustainability is an odd concept - it implies that we can anticipate all variables - both present and future - and factor them into our decision making. As this is extremely difficult, we tend to concentrate on correcting what was wrong with previous approaches, or on how we can appease the present self-interests of all of those involved. I call this the McDonald's pizza approach - take all of the ingredients and try them in different combinations until you get a product that is palatable to the greatest number of people. The result is generally bland and without risk.

The major shortcoming of this approach is that it concentrates on what is acceptable or necessary today, or worse, what was wrong yesterday. However, the values of Canadians and the demands they are placing upon our forests have changed dramatically within one rotation in the forest. No one predicted that. Industry and governments were unprepared for that change. Environmental issues are only the latest in an escalating series of expressions of public concern. What will be next?

What situation will a tree planted today encounter when it reaches maturity? We all know that the values of society and the issues of concern to the public will change again, perhaps even more dramatically. In order to prevent a reoccurrence of the present situation, forest management planning needs to look to the future and not to the past.

Ontario is moving in this direction by incorporating the concept of "future forest condition" into forest management planning. This, however, only addresses the ecological structure of forests. We are unable to predict the changing mix of values and demands on the forests that may coincide with the attainment of the desired forest condition, which may undermine our best efforts. If industry wants to assure a supply of timber for the future, though, it must attempt to address these uncertainties in its planning and operations. In all of the confusion surrounding sustainable forest management, there is tremendous opportunity, and the time is right for progressive forest companies to step up and demonstrate leadership in moving towards the new era in forest management that we are all talking about, instead of whining about the constraints being imposed upon them.

\section{A Proactive Approach to Timber Supply}

The allocation of forests for timber is no longer assured, and industry is only one player in the forests. Timber supply will no longer be given; it must be earned. Timber supply will only be secure if the industry can regain the public's trust and confidence. If industry wants to ensure continued access to the quantity and quality of timber it requires, it needs to do several things.

Firstly, the industry must demonstrate good corporate citizenship in the woods. This means setting an example in all aspects of forest operations, and going beyond mere compliance or the standards established by competitors. It means welcoming certification programs that set the highest possible targets for sustainable forest management. It does not mean being content with the status quo, or trying to enshrine present approaches as the ideal. They obviously aren't.

Secondly, industry must clearly express its needs. The public views the industry as a voracious monster gobbling up Canada's forests - an image that is hard to dispel when the area of Canada licensed to timber companies and the steep increase in roundwood production over the past forty years are considered. Claiming most of the accessible forests for timber production and then having other users claw back little bits for parks, stream buffers or viewscapes is no longer acceptable. Other users are continually challenged to identify how much of the forest they need, yet industry never discloses its requirements. Industry needs to take a good hard look at what it needs and clearly communicate how much fibre it requires and where and how that fibre might be sourced, instead of working backwards from $100 \%$.

Most importantly, industry needs to open the doors and engage the public - not through salesmanship or public relations, but by providing for meaningful public involvement in planning and decision making. This is the only way in which a dynamic and productive relationship with others who value the forests can be established. Only through such interaction can industry anticipate and respond to changing public demands and values, and be in a position to act rather than react to changing public values and demands. 
The latter point is key. There are three basic approaches to resolving forest disputes. Governments can act as intermediaries, and can allocate forests to the best of their ability to industry and other users, and regulate them accordingly. Alternately, the public can take its concerns to the courts, as happens in much of the USA, where the issues are played out in an adversarial situation with a judge deciding.

A preferable solution is to drop the intermediary and get the public on the same side as the industry. This means bringing interested parties to the table early in the planning process, listening to them, and reflecting their concerns in forest management planning. It also means looking for partnership opportunities in forest operations and management. Critics may find that many of the things they thought were problems are not really that serious. Many may even lose interest. Industry, on the other hand, may receive a lot of new insights and ideas that can help improve corporate performance.
Best of all, all parties will develop trust and confidence and a healthy working relationship that will assist them to identify real, as opposed to perceived, areas of disagreement and to resolve them in a proactive fashion. Only if those who are fearful of the loss of our forests, or of the loss of the values they expect from the forests, are actively engaged in forest management planning and operations will the necessary trust be built to ensure a long term supply of timber to the industry.

Timber supply is as much about values as it is about the quantity and quality of trees. Ensuring a predictable supply of timber to mills therefore requires consideration of the needs and wants of the society of the future. This can only be obtained by involving the society of today in forest management planning and by allowing for continual adaptation to the changing wants and needs of all those who care about the forests. 